\title{
Strengthening Low Plastic Soils Using Micro Fine Cement through Deep Mixing Methodology
}

\author{
Manish V. Shah ${ }^{1, *}$ Parth $\mathrm{Shah}^{1}$, and Abhay R Gandhi ${ }^{1}$ \\ ${ }^{1}$ Applied Mechanics, L.D. College of Engineering, Ahmedabad 380015, Gujarat, India
}

\begin{abstract}
Present research papers focuses to strength low plastic soil using deep cement mixing technique through model study. Soil column length of $10 \mathrm{~cm}, 20 \mathrm{~cm}$ and $30 \mathrm{~cm}$ was used with varying degree of saturation as $60 \%, 80 \%$ and $100 \%$ of $\mathrm{OMC}$ to determine settlement characteristics, unconfined compressive strength, modulus of subgrade reaction and modulus of elasticity of raw and treated soil. Cement dosage for UCS test and model plate load test was decided as per guidelines provided in FHWA 13-046 design manual and CDMLODIC method respectively. Method of deep mixing the soil with cement was adopted from theory given by Filz et.al. (2005). The results depicted the cement deep mixing methodology based on soil particle-cement particle interaction with varying degree of saturation proved the efficacy for low plastic soils and maximum reduction in settlement was observed for $60 \%$ degree of saturation for column length of $20 \mathrm{~cm}$. Modulus of elasticity was validated with provisions of FHWA whereas load carrying capacity of soil-cement column was validated with Broms empirical equation.
\end{abstract}

\section{Introduction}

Deep Soil Mixing technique was developed in 1970's in Japan and is now extensively used in countries like USA, France, etc. Deep soil mixing can be characterized into 23 different techniques like Cement Deep Mixing (CDM), Wet Deep Mixing Method (WDMM), Dry Deep Mixing Method (DDMM), etc. There is a difference between pressure grouting or jet grouting and wet deep mixing technique, in the former the binder is injected into the soil under a certain pressure head whereas in the latter the soil is filled under a certain static head and mixed under a particular rotational head depending on the degree of mixing as well as strength required as shown by Filz. [1].

The present research emphasizes on studying the effectiveness of cement deep mixing (CDM) technique on soil compacted at different degrees of saturation. The mechanical behaviour of strengthened soil varies considerably is greatly affected by method used for preparation of specimen [2]. CDM technique can further be classified into two different methods namely: CDM method and CDM- LODIC method, in the former the cement dosage is fixed as per strength requirement [3], whereas in the latter the cement dosage is fixed on the basis of weight of soil excavated from the hole drilled. In the present study soil was compacted at $90 \%$ of maximum dry density and at varying degree of saturation as $60 \%$, $80 \%$ and $100 \%$ of optimum moisture content, also the soil-cement column length were varied as $10 \mathrm{~cm}, 20 \mathrm{~cm}$ and $30 \mathrm{~cm}$ and its unconfined compression strength as well as settlement facet were studied. For the purpose of evaluating the compression strength, unconfined compression strength test was carried out whereas for evaluating the settlement facet as well as the modulus of subgrade reaction and modulus of elasticity of soil, indigenously modelled plate load test was carried out. The cement dosage for performing the unconfined compression strength test was fixed on basis of guidelines given in FHWA 13-046 Design Manual [4]; on the other hand cement dosage for evaluating the settlement facet was on the basis of CDM- LODIC method.

\section{Deep Mixing Technique \& Materials}

Topolnicki [5] classified the Deep Soil Mixing (DSM) technique in three levels taking into consideration dry and wet deep mixing method. These are mainly: (1) Mechanical, hydraulic or hybrid way of mixing; (2) position of mixing; (3) axis of rotation of the tool. The entire procedure of wet deep mixing mainly involves four stages; these can be summarized as follows:

(1) Insertion of temporary casing into the soil

(2) Introducing the tool into the installed casing

(3) Spreading of the tool and soil mixing

(4) Withdrawl of the assembly.

Commencement of the above four steps leads to the formation of a rigid soil-cement column which improvises the soil to a very great extent.

\subsection{Deep mixing assembly}

For fulfilling the purpose of deep mixing an assembly was fabricated which comprised of a solid shaft of $25 \mathrm{~mm}$ diameter with perforations all around its circumference, a

\footnotetext{
* Corresponding author: mvs2212@yahoo.co.in
} 
cutter blade with width of $50 \mathrm{~mm}$ to facilitate drilling of $50 \mathrm{~mm}$ diameter hole. Shaft was reduced to a diameter of $12.5 \mathrm{~mm}$ at top in order to facilitate fixing of the assembly on the hand drill. Filling of the hole by cement slurry was commenced during the withdrawal of the assembly. The assembly consisted of an inlet at the top and perforations over the circumference of the solid pipe which proved to be advantageous in achieving the desired mixing between the soil and the cement.

\subsection{Soil and binder}

Properties of low plastic soil investigated are tabulated in table 1 as follows:

Table 1. Physical properties of soil \& binder

\begin{tabular}{|c|c|}
\hline Properties & Results \\
\hline Specific Gravity & 2.7 \\
\hline Liquid Limit (\%) & 32 \\
\hline Plastic Limit (\%) & 21 \\
\hline Soil Classification (IS) & Low Plastic Clay \\
\hline Free Swell Index (\%) & 9.09 \\
\hline Cohesion (kg/cm $\left.{ }^{2}\right)$ & 0.5 \\
\hline Angle of internal friction $\left({ }^{\circ}\right)$ & 23 \\
\hline Optimum Moisture Content $(\%)$ & 12.8 \\
\hline Maximum Dry Density (kN/m $\left.{ }^{3}\right)$ & 19.55 \\
\hline Microfine Cement & 12000 SSA \\
\hline
\end{tabular}

The soil was classified as low plastic clay as per Indian Standards with a clay content of $14.52 \%$.

\subsection{Test set-up}

Actual setup is presented in Figure 1 which shows the mechanical jack, proving ring with a capacity of $50 \mathrm{kN}$, rod attached at the base of the proving ring which acts as a medium to transfer the load from mechanical jack to the aluminium footing model.

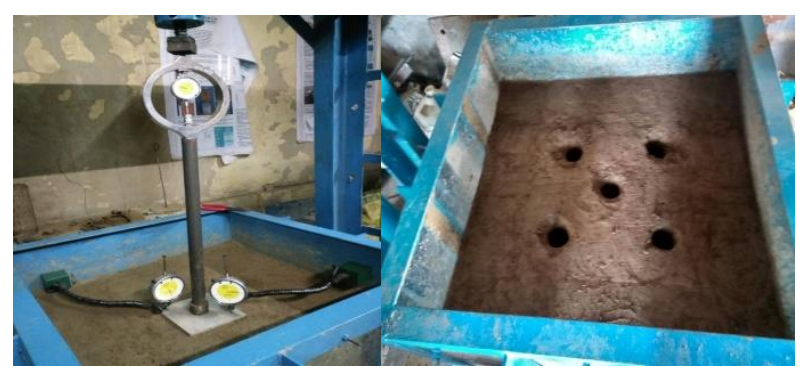

Fig. 1. Model Test-setup and bores of soil-cement column

\subsubsection{Preparation of soil-cement column}

Water to cement ratio on the basis of trial and error was selected to be 1.2 since it provided a desired workable mix which can be easily poured into the inlet of the assembly. Five soil-cement columns were drilled and mixed among which four columns were spaced equally at $25 \mathrm{~cm}$ centre to centre distance and one exactly under the footing. Soilcement column had a fixed diameter of $5 \mathrm{~cm}$ and length was varied as $10 \mathrm{~cm}, 20 \mathrm{~cm}$ and $30 \mathrm{~cm}$. Figure 5 represents the drilled soil-cement columns in the fabricated tank. The cement dosages for a column length of $10 \mathrm{~cm}, 20 \mathrm{~cm}$ and $30 \mathrm{~cm}$ on the basis of CDM-LODIC method are tabulated in Table 2 .

Table 2. Cement dosage as per CDM-LODIC method

\begin{tabular}{|c|c|}
\hline $\begin{array}{c}\text { Soil-Cement Column Length } \\
(\mathrm{cm})\end{array}$ & Cement Dosage $(\mathrm{kg})$ \\
\hline 10 & 0.345 \\
\hline 20 & 0.690 \\
\hline 30 & 1.036 \\
\hline
\end{tabular}

\subsubsection{Installation of soil-cement columns}

The soil-cement columns were installed as per the theory suggested by Kitazume[1] and Tersahi[6], and the adopted theory behind fixing the arrangement of the column was also given by Kitazume [1].

\subsubsection{Testing procedure}

Testing was carried out on both treated and un-treated soil and results were compared. In case of untreated soil, load was applied up to reaching the settlement of $25 \mathrm{~mm}$, whereas in case of untreated soil the loading was commenced up to the time when it becomes difficult to rotate the mechanical jack.

\section{Results, Analysis and Discussion}

\subsection{Strength of Treated soil}

Nine samples of unconfined compression strength were prepared and tested to study the effect of degree of saturation on effectiveness of Cement Deep Mixing (CDM) technique on unconfined compression strength of treated soil at a constant water cement ratio and varying cement dosages $[8,9]$. The cement dosages varied along with the water content is obtained using empirical relations presented in FHWA 13-046 [4]. The unconfined compression strength of treated soil under varying degree of saturation at 28 days can be related to cement dosage by equation (1), however this relation between unconfined compression strength at 28 days and the cement dosage is applicable only when the cement dosages are fixed on basis of moisture content of soil corresponding to desired degree of saturation.

$$
q_{u}=-2.342 C D+428.3
$$

As strength of $250 \mathrm{kPa}$ was fixed as desired strength and based on field efficiency criteria as suggested by Euro Soil Stab:2002 [7] the laboratory strength was fixed as $400 \mathrm{kPa}$ and cement dosages were evaluated on basis of guidelines provided in FHWA 13-046. The unconfined 
compression strength values of treated soil at various degree of saturation are shown in Table 3.

Table 3. Unconfined Compression Strength of treated soil for différent degree of saturation

\begin{tabular}{|c|c|c|}
\hline $\begin{array}{c}\text { Degree of } \\
\text { Saturation (\%) }\end{array}$ & $\begin{array}{c}\text { Cement } \\
\text { Dosage } \\
\left(\mathrm{kg} / \mathrm{m}^{3}\right)\end{array}$ & $\begin{array}{c}\text { Unconfined } \\
\text { Compression } \\
\text { Strength }(\mathrm{kPa})\end{array}$ \\
\hline 60 & 50.04 & 314.03 \\
\hline 80 & 66.73 & 266.36 \\
\hline 100 & 83.45 & 235.76 \\
\hline
\end{tabular}

\subsection{Settlement of Treated soil}

Changes in the settlement of treated soil as compared to that of untreated soil as well as to evaluate the modulus of subgrade reaction and modulus of elasticity of soil indigenously developed modelled plate load test was performed. An overall $80 \%$ of reduction in settlement was observed in treated soil as compared to untreated soil. The final values of settlement at the same load for untreated and treated soil are tabulated in Table 4. Better results were obtained at a lower degree of saturation and for a soil-cement column length of $20 \mathrm{~cm}$.

Table 4. Settlement values for untreated and treated soil under same loading condition

\begin{tabular}{|c|c|c|c|}
\hline $\begin{array}{c}\text { Degree of } \\
\text { Saturation } \\
(\%)\end{array}$ & $\begin{array}{c}\text { Soil- } \\
\text { Cement } \\
\text { Column } \\
\text { length } \\
(\mathrm{cm})\end{array}$ & $\begin{array}{c}\text { Settlement } \\
(\mathrm{mm})\end{array}$ & $\begin{array}{c}\text { Percentage } \\
\text { reduction in } \\
\text { settlement }\end{array}$ \\
\hline $\begin{array}{c}\text { At OMC } \\
\text { (Untreated) }\end{array}$ & None & 29.52 & None \\
\hline \multirow{2}{*}{$\begin{array}{c}60 \\
(\text { Treated })\end{array}$} & 10 & 4.915 & 83.35 \\
\cline { 2 - 4 } & 20 & 3.085 & 89.55 \\
\hline \multirow{3}{*}{$\begin{array}{c}80 \\
(\text { Treated) }\end{array}$} & 30 & 6.5 & 77.98 \\
\cline { 2 - 4 } & 10 & 5.42 & 81.64 \\
\hline \multirow{2}{*}{$\begin{array}{c}\text { At OMC } \\
\text { (Treated) }\end{array}$} & 20 & 3.89 & 86.82 \\
\cline { 2 - 4 } & 30 & 6.702 & 77.29 \\
\hline
\end{tabular}

It can be seen from the values tabulated above that for soil-cement column length of $30 \mathrm{~cm}$ and diameter as $5 \mathrm{~cm}$ which leads to length to diameter ratio of 6 the settlement values are higher as compared to that of rest of treated soil-cement column lengths.

\subsection{Effect of degree of saturation}

The increase in degree of saturation for a particular length of soil-cement column the reduction in settlement decreases which confirms that soil compacted at dry side of optimum provides better result even for shorter length of soil-cement column. It should be however noted that no matter the settlement for soil-cement column length of 30 $\mathrm{cm}$ are higher than that of $10 \mathrm{~cm}$ and $20 \mathrm{~cm}$ but as degree of saturation was reduced from $80 \%$ to $60 \%$ the settlement for $30 \mathrm{~cm}$ column length also reduced.

\subsection{Effect of soil column length}

For a given degree of saturation with increase in soilcement column length the reduction in settlement increases, however the results for soil-cement column length of $30 \mathrm{~cm}$ were quite unexpected, at a given degree of saturation the settlement was no doubt much lesser than that of untreated soil but was greater than that of $10 \mathrm{~cm}$ soil-cement column.

\subsection{Evaluation of modulus of subgrade reaction and modulus of elasticity}

After analyzing the reduction in settlement of soil under various conditions next parameters analyzed in this study are the modulus of subgrade reaction and modulus of elasticity of soil. Modulus of subgrade reaction was evaluated by taking in reference the methods provided in IS 9214:1979. For evaluating modulus of elasticity of soil two empirical relation on basis of elastic theory, this relation is represented in equations.

$$
\begin{aligned}
& k=4 E / \pi d\left(1-\mu^{2}\right) \\
& k=0.65 E /\left(B\left(1-\mu^{2}\right) *\left(B^{*} E / E I\right)^{1 / 12}\right.
\end{aligned}
$$

The values of modulus of subgrade reaction and modulus of elasticity evaluated using above empirical relations are tabulated in Table 5 below.

Table 5. Modulus of subgrade reaction and modulus of elasticity of treated soil

\begin{tabular}{|c|c|c|c|}
\hline $\begin{array}{c}\text { Degree of } \\
\text { Saturation } \\
(\%)\end{array}$ & $\begin{array}{c}\text { Soil- } \\
\text { Cement } \\
\text { Column } \\
\text { length } \\
(\mathrm{cm})\end{array}$ & $\begin{array}{c}\text { Modulus of } \\
\text { subgrade } \\
\text { reaction k } \\
\left(\mathrm{kg} / \mathrm{cm}^{2} / \mathrm{cm}\right)\end{array}$ & $\begin{array}{c}\text { Modulus } \\
\text { of } \\
\text { elasticity E } \\
\left(\mathrm{kg} / \mathrm{cm}^{2}\right)\end{array}$ \\
\hline $\begin{array}{c}\text { At OMC } \\
\text { (Untreated) }\end{array}$ & None & 4.44 & 47.59 \\
\hline \multirow{2}{*}{$\begin{array}{c}60 \\
(\text { Treated) }\end{array}$} & 10 & 7.38 & 83.46 \\
\cline { 2 - 4 } & 20 & 7.70 & 87.08 \\
\hline \multirow{2}{*}{$\begin{array}{c}80 \\
(\text { Treated) }\end{array}$} & 30 & 5.63 & 63.67 \\
\cline { 2 - 4 } & 10 & 7.40 & 79.33 \\
\hline \multirow{2}{*}{$\begin{array}{c}\text { At OMC } \\
\text { (Treated) }\end{array}$} & 10 & 7.69 & 82.44 \\
\cline { 2 - 4 } & 20 & 5.33 & 60.28 \\
\cline { 2 - 4 } & 30 & 5.03 & 53.92 \\
\hline
\end{tabular}

\section{Summary of findings}

The following summary of findings has been summarized as under: 
- As the moisture content of the soil approaches the optimum moisture content, strength of the treated soil reduces.

- With increase in cement dosage, unconfined compression strength was found to reduce, the main reason behind this being increase in cement dosage was totally dependent on moisture content pertaining to the required degree of saturation, and since with increase in degree of saturation strength reduced it followed the same trend with cement dosage as well.

- For a given degree of saturation of the soil, with the increase in the soil-cement column length about $30 \%$ to $35 \%$ more reduction in settlement was observed.

- For a given soil-cement column length, with the increase in the degree of saturation of soil, the percentage reduction in settlement was recorded to decline by $10 \%$ to $15 \%$.

- At same degree of saturation, with the increase in the soil-cement column length modulus of subgrade reaction was found to increase by $5 \%$ to $7 \%$

- For the same column length, with decrease in degree of saturation modulus of subgrade reaction was found to increase by $45 \%$ to $50 \%$.

- For the same column length, with decrease in degree of saturation modulus of elasticity of soil was found to increase by $45 \%$ to $50 \%$.

- At same degree of saturation, with the increase in the soil-cement column length modulus of elasticity of soil was found to increase by $4 \%$ to $6 \%$.

- Soil-Cement column length of $30 \mathrm{~cm}$ showed some unexpected results in which the settlement although was lesser than that of untreated soil but it showed about $20 \%$ more settlement than column length of $10 \mathrm{~cm}$ at same degree of saturation

- Modulus of subgrade reaction and modulus of elasticity of soil treated using a soil-cement column length of $30 \mathrm{~cm}$ also reduced by nearly $20 \%$ to $25 \%$.

- Length to Diameter ratio of 6 can be considered to be ineffective; however the study of length to diameter ratio post testing is also important.

- The difference in values of modulus of subgrade reaction of soil compacted with a moisture content corresponding to $60 \%$ and $80 \%$ saturation was negligible, however value of modulus of elasticity showed a little difference.

- As per guidelines provided in FHWA HRT 13-046 the ratio of modulus of elasticity to unconfined compression strength of treated soil should lie in the range of 75 to 300 . On evaluating the ratios of modulus of elasticity and unconfined compression strength of treated samples it worked out to be 77,92 and 75 for $60 \%, 80 \%$ and $100 \%$ degree of saturation respectively.

- Validation for bearing capacity was carried out using the empirical relation as suggested by Broms [10] considering soil-cement columns as piles. Broms equation takes into account only the effect of degree of saturation and not of soil-cement column length. Bearing capacity of each soil-cement column obtained theoretically are $0.885 \mathrm{~kg} / \mathrm{cm}^{2}, 0.875 \mathrm{~kg} / \mathrm{cm}^{2}, 0.869$ $\mathrm{kg} / \mathrm{cm}^{2}$ for degree of saturation as $60 \%, 80 \%$ and $100 \%$ respectively, whereas the bearing capacity evaluated experimentally at same degrees of saturation are 1.042 $\mathrm{kg} / \mathrm{cm}^{2}, 0.97 \mathrm{~kg} / \mathrm{cm}^{2}, 0.92 \mathrm{~kg} / \mathrm{cm}^{2}$.

Thus, compacting the soil on dry side of optimum with length of soil-cement column such that length to diameter ratio of nearly 4 was found to be optimum.

It can thus be concluded that Cement Deep Mixing (CDM) technique when applied on low plastic soils subjected to variation in degree of saturation gives satisfactory results. Use of microfine cement as a binder for low plastic soils was found to be adequate for a suitable water to cement ratio selected. Various assumptions regarding the length of soil-cement column were made in the study due to lack of particular Indian Codal guidelines on CDM technique, the assumptions made provided adequate results except that for soilcement column length of $30 \mathrm{~cm}$, thus indicating the feasibility of CDM technique as a modern ground improvement technique for low plastic soil especially when soil is compacted on dry side of optimum.

The authors are thankful to Dr. G. P. Vadodaria for providing all the research facilities required for the successful accomplishment of this project work.

\section{References}

1. Filz G. M. et.al. Standardized definitions and laboratory procedures for soil cement specimens applicable to wet method of deep mixing, GeoFrontiers Congress, ASCE, 162, 1 (2005)

2. M. Kitazume et.al, The Japanese Geotechnical Society- Elsevier, 55761, 777 (2015)

3. I. A Mostafa et.al, ASCE, 128, 6, 520-529 (2002)

4. Federal Highway Administration Design Manual: Deep Mixing for Embankment and Foundation Support, FHWA-HRT-13-046 (2013)

5. M. Topolnicki et.al, Grouting and Deep Mixing, ASCE, 228, 1, 533-542 (2012)

6. M. Terashi Theme lecture: Deep mixing methodBrief state of the art., $4^{\text {th }}$ Proceedings of the International Conference on Soil Mechanics and Foundation Engineering, Hamburg, 2475-2478 (1997)

7. EuroSoilStab (2002), Design guide soft soil stabilization, CT97-0351

8. D. A. Bruce, Practitioner's guide to deep mixing, Ground Improvement, 5, 3, 95-100 (2001)

9. Coastal Development Institute of Technology (CDIT), (2002), The Deep Mixing Method: Principle, Designed Construction

10. B. Broms, Deep soil stabilization: design and construction of lime and lime/cement columns, Stockholm: Royal Institute of Technology (2003) 